\title{
Impact of land cover uncertainties on estimates of biospheric carbon fluxes
}

T. Quaife, ${ }^{1,2}$ S. Quegan, ${ }^{1,3}$ M. Disney, ${ }^{1,2}$ P. Lewis, ${ }^{1,2}$ M. Lomas, ${ }^{1,4}$ and F. I. Woodward ${ }^{1,4}$

Received 30 August 2007; revised 28 May 2008; accepted 8 August 2008; published 4 December 2008.

[1] Large-scale bottom-up estimates of terrestrial carbon fluxes, whether based on models or inventory, are highly dependent on the assumed land cover. Most current land cover and land cover change maps are based on satellite data and are likely to be so for the foreseeable future. However, these maps show large differences, both at the class level and when transformed into Plant Functional Types (PFTs), and these can lead to large differences in terrestrial $\mathrm{CO}_{2}$ fluxes estimated by Dynamic Vegetation Models. In this study the Sheffield Dynamic Global Vegetation Model is used. We compare PFT maps and the resulting fluxes arising from the use of widely available moderate $(1 \mathrm{~km})$ resolution satellite-derived land cover maps (the Global Land Cover 2000 and several MODIS classification schemes), with fluxes calculated using a reference high $(25 \mathrm{~m})$ resolution land cover map specific to Great Britain (the Land Cover Map 2000). We demonstrate that uncertainty is introduced into carbon flux calculations by (1) incorrect or uncertain assignment of land cover classes to PFTs; (2) information loss at coarser resolutions; (3) difficulty in discriminating some vegetation types from satellite data. When averaged over Great Britain, modeled $\mathrm{CO}_{2}$ fluxes derived using the different $1 \mathrm{~km}$ resolution maps differ from estimates made using the reference map. The ranges of these differences are $254 \mathrm{gC} \mathrm{m}^{-2} \mathrm{a}^{-1}$ in Gross Primary Production (GPP); $133 \mathrm{gC} \mathrm{m}^{-2} \mathrm{a}^{-1}$ in Net Primary Production (NPP); and $43 \mathrm{gC} \mathrm{m}^{-2} \mathrm{a}^{-1}$ in Net Ecosystem Production (NEP). In GPP this accounts for differences of $-15.8 \%$ to $8.8 \%$. Results for living biomass exhibit a range of $1109 \mathrm{gC} \mathrm{m}^{-2}$. The types of uncertainties due to land cover confusion are likely to be representative of many parts of the world, especially heterogeneous landscapes such as those found in western Europe.

Citation: Quaife, T., S. Quegan, M. Disney, P. Lewis, M. Lomas, and F. I. Woodward (2008), Impact of land cover uncertainties on estimates of biospheric carbon fluxes, Global Biogeochem. Cycles, 22, GB4016, doi:10.1029/2007GB003097.

\section{Introduction}

[2] A fundamental element in understanding the current and future behavior of the Earth system is the terrestrial carbon cycle [Schimel, 1995; Meir et al., 2006]. On average, around $30 \%$ of the carbon dioxide emitted from fossil fuel burning and biomass burning is taken up by the terrestrial biosphere [IPCC, 2001], but this flux exhibits large interannual variability and great uncertainties in its size, location and the controlling mechanisms. One of the key controls on land-atmosphere carbon fluxes is land cover, which is itself highly dependent on climate and the nature and amount of human interference [Foley et al., 2005; Sitch et al., 2005]. Almost all current land cover and land cover change maps

\footnotetext{
${ }^{1}$ Centre for Terrestrial Carbon Dynamics, Natural Environment Research Council, University of Sheffield, Sheffield, UK.

${ }^{2}$ Department of Geography, University College London, London, UK.

${ }^{3}$ Department of Applied Mathematics, University of Sheffield, Sheffield, UK.

${ }^{4}$ Department of Animal and Plant Sciences, University of Sheffield, Sheffield, UK.

Copyright 2008 by the American Geophysical Union. 0886-6236/08/2007GB003097
}

are largely based on satellite data, and are likely to be so for the foreseeable future. It is therefore of considerable importance to know the properties and limitations of such maps for use in carbon flux calculations, and how uncertainties in these maps lead to flux uncertainties.

[3] Land cover information can be combined with average fluxes from different cover types in order to estimate regional fluxes [Janssens et al., 2003]. However, a more fundamental approach is adopted by Dynamic Vegetation Models (DVMs), which integrate process understanding with many types of data, including land cover, in order to produce carbon flux estimates. DVMs have become essential tools for analyzing the response of vegetation to both current climate and future climate scenarios [Bonan et al., 2002; Cramer et al., 2001].

[4] DVMs usually represent land cover in a generalized form where vegetation is grouped into a small number of plant functional types (PFTs). Species belonging to a given PFT are assumed to respond similarly under given environmental conditions. This not only reduces the computational load (an important consideration given the high computing demands of global simulations) but can also help in interpreting the calculations. In some DVMs, the spatial distri- 
Table 1a. Classes Represented Within Each of the SatelliteDerived Land Cover Products and the PFTs to Which They are Assigned: LCM2000a

\begin{tabular}{|c|c|}
\hline PFT & Classes \\
\hline Deciduous & $\begin{array}{l}\text { broadleaved woodlands; dwarf shrub heath; } \\
\text { open dwarf shrub heath }\end{array}$ \\
\hline Evergreen & coniferous woodland \\
\hline C3 grasses & $\begin{array}{l}\text { improved grassland; set aside grass land; } \\
\text { neutral grass; calcareous grass; } \\
\text { acid grass; bracken; fen, marsh, swamp; } \\
\text { bog; montane habitats; salt marsh }\end{array}$ \\
\hline Crops & $\begin{array}{l}\text { arable cereals; arable horticulture; } \\
\text { nonrotational horticulture }\end{array}$ \\
\hline Bare/urban & $\begin{array}{l}\text { sea; water (inland); inland bare ground; } \\
\text { suburban/rural development; } \\
\text { continuous urban; supra littoral rock; } \\
\text { supra littoral sediment; } \\
\text { littoral rock; littoral sediment; sea/estuary }\end{array}$ \\
\hline
\end{tabular}

${ }^{a}$ Land cover classes belonging to two Plant Functional Types (PFTs) are marked with an asterisk in Tables $1 \mathrm{~b}, 1 \mathrm{c}, 1 \mathrm{e}, 1 \mathrm{f}$, and $1 \mathrm{~g}$. In this case the land cover is split equally into each PFT.

bution of PFTs can be calculated internally under a set of competition rules between PFTs; this is necessary, for example, to investigate the natural progression of vegetation under climate change (see Bonan et al. [2002] for application at very coarse scales). Such an approach fails to capture the enormous amount of human management of the land surface, whose description requires land cover maps, preferably as time series for the whole of a simulated time period. Hence most DVMs take advantage of land cover products to constrain their calculations.

[5] Satellite data are the most important source of information on contemporary land cover. Global land cover products were first derived from satellites using NOAA Advanced Very High Resolution Radiometer (AVHRR) data at a nominal spatial resolution of $1 \mathrm{~km}$ [Townshend, 1994]. Since then, a variety of global land cover products have been provided to the scientific community, but they often show poor agreement at the regional or per-pixel scale [Giri et al., 2005; Hansen and Reed, 2000; See and Fritz, 2006]. Such disagreements arise because different products may be produced from different source data covering different time periods and using different classification methods [McCallum et al., 2006]. However, they also reflect intrinsic limitations in our ability to distinguish different cover types from any given satellite data set. The purpose of this paper is to quantify the uncertainty introduced into DVM estimates of carbon fluxes by these limitations.

[6] Previous studies have examined how land cover representation effects estimates of carbon flux, but only for simple production efficiency models [Reich et al., 1999] or methods based on multiplying empirically derived average fluxes for given cover types by their area [Turner et al., 2000]. Neither method represents the soil-vegetation system adequately and hence neither has prognostic capabilities. In this paper we instead use a state-of-the-art process-based DVM, the Sheffield Dynamic Global Vegetation Model [Woodward and Lomas, 2004], to estimate three types of carbon flux: Gross Primary Production (GPP), the gross uptake of carbon by photosynthesis; Net Primary Production (NPP), the net uptake after autotrophic respiration and;
Net Ecosystem Production (NEP): the net uptake after heterotrophic and autotrophic respiration. The results show how uncertainties in widely used global land cover products translate into uncertainties in model estimates of these fluxes. Great Britain is used as a test case, since there exists a validated high-resolution land cover map that is used as a reference against which to compare calculations on the basis of other land cover data. The conclusions however, have relevance at global scale.

\section{Land Cover Products and Plant Functional Types}

[7] The following sections describe the land cover products used in this paper and how they are transformed into PFT maps.

\subsection{Satellite-Derived Land Cover Products \\ 2.1.1. LCM2000}

[8] This study uses as reference the Land Cover Map 2000 (LCM2000) [Haines-Young et al., 2000], which has $25 \mathrm{~m}$ resolution and contains the classes given in Table 1a. It is derived using data from the Landsat Enhanced Thematic Mapper, Thematic Mapper and the Indian Research Satellite LISS sensors. Although nominally corresponding to the year 2000, cloud cover meant that data from several years had to be combined in its formation (3\% of the map is from $1996,17 \%$ from $1997,47 \%$ from $1998,18 \%$ from 1999 , $13 \%$ from 2000 and 2\% from 2001). While more accurate and more detailed than the products described in sections 2.1 .2 and 2.1.3, it was very labor-intensive to produce and cannot be updated as often. Hence, equivalent high-resolution classifications are available only for a small proportion of the land surface.

\subsubsection{GLC2000}

[9] The Global Land Cover Map 2000 (GLC2000) is a $1 \mathrm{~km}$ resolution product based on the Food and Agriculture Organization Land Cover Classification System [Bartholomé and Belward, 2005]. It is derived from daily values of surface reflectance and the Normalized Difference Vegetation Index

Table 1b. As in Table 1a, for GLC2000

\begin{tabular}{|c|c|}
\hline PFT & Classes \\
\hline Deciduous & $\begin{array}{l}\text { closed deciduous broadleaved forest; } \\
\text { mixed needle-leaved and broadleaved forest*; } \\
\text { mixed closed forest and shrubland*; } \\
\text { closed shrubland; open shrubland }\end{array}$ \\
\hline Evergreen & $\begin{array}{l}\text { closed evergreen needle-leaved forest; } \\
\text { mixed needle-leaved and broadleaved forest*; } \\
\text { mixed closed forest and shrubland* }\end{array}$ \\
\hline C3 grasses & $\begin{array}{l}\text { grassland; mixed grassland and cultivated and } \\
\text { managed areas herbaceous crops nonirrigated* }\end{array}$ \\
\hline Crops & $\begin{array}{l}\text { cultivated and managed areas herbaceous crops } \\
\text { nonirrigated; cultivated and managed areas } \\
\text { herbaceous crops irrigated; permanently } \\
\text { cropped area with rainfed shrubs crops; } \\
\text { mixed grassland and cultivated and managed } \\
\text { areas herbaceous crops nonirrigated* }\end{array}$ \\
\hline Bare/urban & $\begin{array}{l}\text { wetland; bare soil and sparsely vegetated area; } \\
\text { extraction site; unclassified; snow and ice; } \\
\text { water bodies; unclassified; unclassified; } \\
\text { unclassified; unclassified; urban }\end{array}$ \\
\hline
\end{tabular}

${ }^{\mathrm{a}}$ See footnote for Table 1a. 
Table 1c. As in Table 1a, for MODIS BGC ${ }^{\mathrm{a}}$

\begin{tabular}{lc}
\hline \multicolumn{1}{c}{ PFT } & Classes \\
\hline $\begin{array}{l}\text { Deciduous } \\
\text { Evergreen }\end{array}$ & $\begin{array}{c}\text { deciduous broadleaf vegetation } \\
\text { evergreen needleleaf vegetation; } \\
\text { deciduous needleleaf vegetation } \\
\text { C3 grasses }\end{array}$ \\
evergreen broadleaf vegetation; \\
annual grass vegetation* \\
annual broadleaf vegetation; \\
annual grass vegetation*
\end{tabular}

${ }^{\mathrm{a}}$ See footnote for Table 1a.

(NDVI) acquired from November 1999 to December 2000 by the SPOT-4 VEGETATION instrument. The institutions responsible for generating GLC2000 over different parts of the globe were allowed to employ their own methodologies, which varied regionally but conformed to a common set of target classes. GLC2000 classes present in Great Britain are listed in Table $1 \mathrm{~b}$.

\subsubsection{MODIS}

[10] The following MODIS land cover products [Strahler et al., 1999] are used: The International BiosphereGeosphere Programme (IGBP) [Loveland and Belward, 1997] and the University of Maryland modification of the IGBP (UMD) [Hansen et al., 2000] classification that aim to provide continuity with earlier land cover maps generated from NOAA AVHRR data that are not considered in this paper. The LAI/fAPAR land cover optimized for the MODIS Leaf Area Index and fraction of Absorbed Photosynthetically Active Radiation algorithm [Lotsch et al., 2003]. A land cover optimized for the BGC model-derived MODIS NPP product [Running et al., 1999]. A PFT classification for use with climate models [Bonan et al., 2002]. Tables 1c-1g list the classes in each of these schemes. Unlike GLC2000, each MODIS product is generated using a single globally applied methodology from 12 months of data acquired in 2001.

\subsection{Transforming Land Cover Classes Into Plant Functional Types}

[11] The model calculations in this paper use grid cells that are $1 / 6^{\circ}$ in latitude and longitude, since this is the grid spacing of the input climate data. The proportion of each class within each grid cell can be represented by a vector, $\mathbf{l}$, calculated by summing the number of $1 \mathrm{~km}^{2}$ pixels in each land cover class within the cell (this destroys any information about the location of cover types within each grid cell, but this information is not used by the model). The

Table 1d. As in Table 1a, for MODIS PFT ${ }^{\mathrm{a}}$

\begin{tabular}{ll}
\hline \multicolumn{1}{c}{ PFT } & \multicolumn{1}{c}{ Classes } \\
\hline Deciduous & deciduous broadleaf trees; Shrub \\
Evergreen & evergreen needleleaf trees; \\
& Deciduous needleleaf trees \\
C3 grasses & evergreen broadleaf trees; Grass \\
Crops & cereal crop; Broadleaf crop \\
Bare/Urban & urban and built up; Snow and Ice; \\
& Barren or sparse vegetation \\
\hline
\end{tabular}

\footnotetext{
${ }^{\mathrm{a}}$ See footnote for Table 1a.
}

Table 1e. As in Table 1a, for MODIS UMD ${ }^{\mathrm{a}}$

\begin{tabular}{|c|c|}
\hline PFT & Classes \\
\hline Deciduous & $\begin{array}{l}\text { deciduous broadleaf forest; mixed forests*; } \\
\text { closed shrublands; open shrublands*; } \\
\text { woody savannas* }\end{array}$ \\
\hline Evergreen & $\begin{array}{l}\text { evergreen needleleaf forest; mixed forests*; } \\
\text { deciduous needleleaf forest }\end{array}$ \\
\hline C3 grasses & $\begin{array}{l}\text { evergreen broadleaf forest; open shrublands*; } \\
\text { woody savannas*; savannas; grasslands }\end{array}$ \\
\hline Crops & croplands \\
\hline Bare/Urban & urban and built up; barren or sparsely vegetated \\
\hline
\end{tabular}

${ }^{\mathrm{a}} \mathrm{See}$ footnote for Table 1a.

corresponding PFT vector, $\mathbf{p}$, is then derived by simple matrix multiplication:

$$
\mathbf{p}=\mathbf{T} \mathbf{l} .
$$

In the SDGVM representation for Great Britain, $\mathbf{p}=(p 1$, $\ldots, p 5)$ has five elements corresponding to deciduous broadleaf, evergreen needleleaf, C3 grasses, crops, and an additional noncontributing PFT representing urban areas and bare ground. These are described in more detail in section 3.1. $\mathbf{T}$ is the matrix that defines the transformation between land cover classes and PFTs for a given land cover product. The relevant transforms are given in Tables $1 \mathrm{a}-1 \mathrm{~g}$, and the resulting maps of proportional PFT are shown in Figure 1 for each land cover product.

[12] Several points should be noted about these transformations. In some cases, a single land cover class needs to be assigned to several PFTs. For example, GLC2000 has a "mixed needleleaf and broadleaf forest" class. Such classes are split equally between the component PFTs. When the land cover map specifies needleleaf or broadleaf trees but does not distinguish between evergreen and deciduous, all the needleleaf is assigned to the evergreen needleleaf PFT and all the broadleaf to the broadleaf deciduous PFT. This is appropriate in Great Britain, which has few areas of evergreen broadleaf or deciduous needleleaf forest, but different rules would be required elsewhere in the world. All MODIS land cover schemes except LAI/fAPAR indicate areas of evergreen broadleaf class in Great Britain. As noted above, this is unrealistic, and comparison with LCM2000 suggests that they should be assigned to the $\mathrm{C} 3$ grass PFT. This has a major impact for MODIS-BGC, for which this class covers $\sim 40 \%$ of Great Britain, as compared with no more than $5 \%$ in any of the other MODIS products.

Table 1f. As in Table 1a, for MODIS IGBP ${ }^{\mathrm{a}}$

\begin{tabular}{|c|c|}
\hline PFT & Classes \\
\hline Deciduous & $\begin{array}{l}\text { deciduous broadleaf forest; mixed forests*; } \\
\text { closed shrublands; open shrublands; woody savannas* }\end{array}$ \\
\hline Evergreen & $\begin{array}{l}\text { evergreen needleleaf forest; mixed forests*; } \\
\text { deciduous needleleaf forest }\end{array}$ \\
\hline $\mathrm{C} 3$ grasses & $\begin{array}{l}\text { evergreen broadleaf forest; woody savannas*; savannas; } \\
\text { grasslands; cropland/natural vegetation mosaic* }\end{array}$ \\
\hline Crops & croplands; cropland/natural vegetation mosaic* \\
\hline Bare/Urban & $\begin{array}{l}\text { water; permanent wetlands; urban and built up; } \\
\text { permanent snow and ice; barren or sparsely vegetated }\end{array}$ \\
\hline
\end{tabular}

${ }^{\mathrm{a}} \mathrm{See}$ footnote for Table 1a. 
Table 1g. As in Table 1a, for MODIS LAI/fAPAR ${ }^{\mathrm{a}}$

\begin{tabular}{ll}
\hline \multicolumn{1}{c}{ PFT } & \multicolumn{1}{c}{ Classes } \\
\hline Deciduous & shrubs; broadleaf forest \\
Evergreen & needleleaf forest \\
C3 grasses & grasses/cereal crops*; savanna \\
Crops & grasses/cereal crops*; broadleaf crops \\
Bare/Urban & nonvegetated; urban \\
\hline
\end{tabular}

${ }^{\mathrm{a}}$ See footnote for Table $1 \mathrm{a}$.

MODIS-BGC presents particular problems as it contains no crop class. However, comparison with LCM2000 suggests that is reasonable to assign the entire annual broadleaf and $50 \%$ of the annual grass class in MODIS-BGC to the crop PFT; the remaining $50 \%$ of annual grassland is assigned to the $\mathrm{C} 3$ grass PFT. Because they use global class definitions, some anomalies occur in the MODIS schemes; e.g., the IGBP classification scheme identifies savannah in Great Britain. Such anomalous classes have been assigned to the most appropriate PFT used by the DVM. It is clear that the assignments shown in Tables $1 \mathrm{a}-1 \mathrm{~g}$ are not all clear-cut, and the corresponding uncertainty is a feature of any use of land cover maps within a DVM.

[13] The points described above are additional sources of uncertainty to those in the land cover products themselves and are introduced by the modeler. They will feed through into the carbon calculations. This is considered in the following discussion but generally the translation between land cover class and PFT is straight forward and hence it is not expected that these arbitrary decisions will be the dominant source of differences between carbon flux predictions.

\subsection{Uncertainty in Land Cover Products}

[14] The LCM2000 is the most accurate available land cover map for Great Britain, hence this paper uses it as a reference against which to test and compare the moderate resolution land cover data sets. However, the LCM2000 is (inevitably) not perfect, as can be seen by comparing it with ground survey data. Table 2 provides a compact summary of this comparison in the form of a confusion matrix, which is based on data published by Fuller et al. [2002] but converted into PFT form. The $(i, j)$ th entry in this matrix gives the number of pixels assigned to class $i$ by the LCM 2000 and class $j$ by ground survey, from a total sample of 884 areas. Elements on the leading diagonal represent pixels where the two classifications agree, while off-diagonal elements indicate the type and number of incidences of class confusion. By way of example, Table 2 shows that 72 pixels are classified as deciduous broadleaf in both the LCM2000 and the field survey data, but that 38 pixels classified as C3 grass in the LCM2000 were reported as deciduous broadleaf in the field survey. The overall accuracy of the LCM2000, defined as the proportion of pixels agreeing with field survey, is $76.9 \%$. The principal misclassifications are between the deciduous broadleaf and $\mathrm{C} 3$ grass PFTs, mainly due to confusion between shrubland (which is assigned to the deciduous PFT) and grasses. Similar effects are seen in the GLC2000 and MODISBGC classifications. Possible causes of such confusion are discussed below.
[15] The proportion of Great Britain covered by each of the PFTs, according to each land cover product, is shown in Table 3. Compared with LCM2000, all the land cover products except MODIS-BGC slightly overestimate the total amount of $\mathrm{C} 3$ grasses and crops by between $4 \%$ and $11.5 \%$, but significantly overestimate how much of this total consists of crops (for LCM2000 it is 38\%, while the other land cover products give values between $57 \%$ and $89 \%$ ). This indicates the difficulty of separating the grass and crop PFTs in multispectral satellite data and a

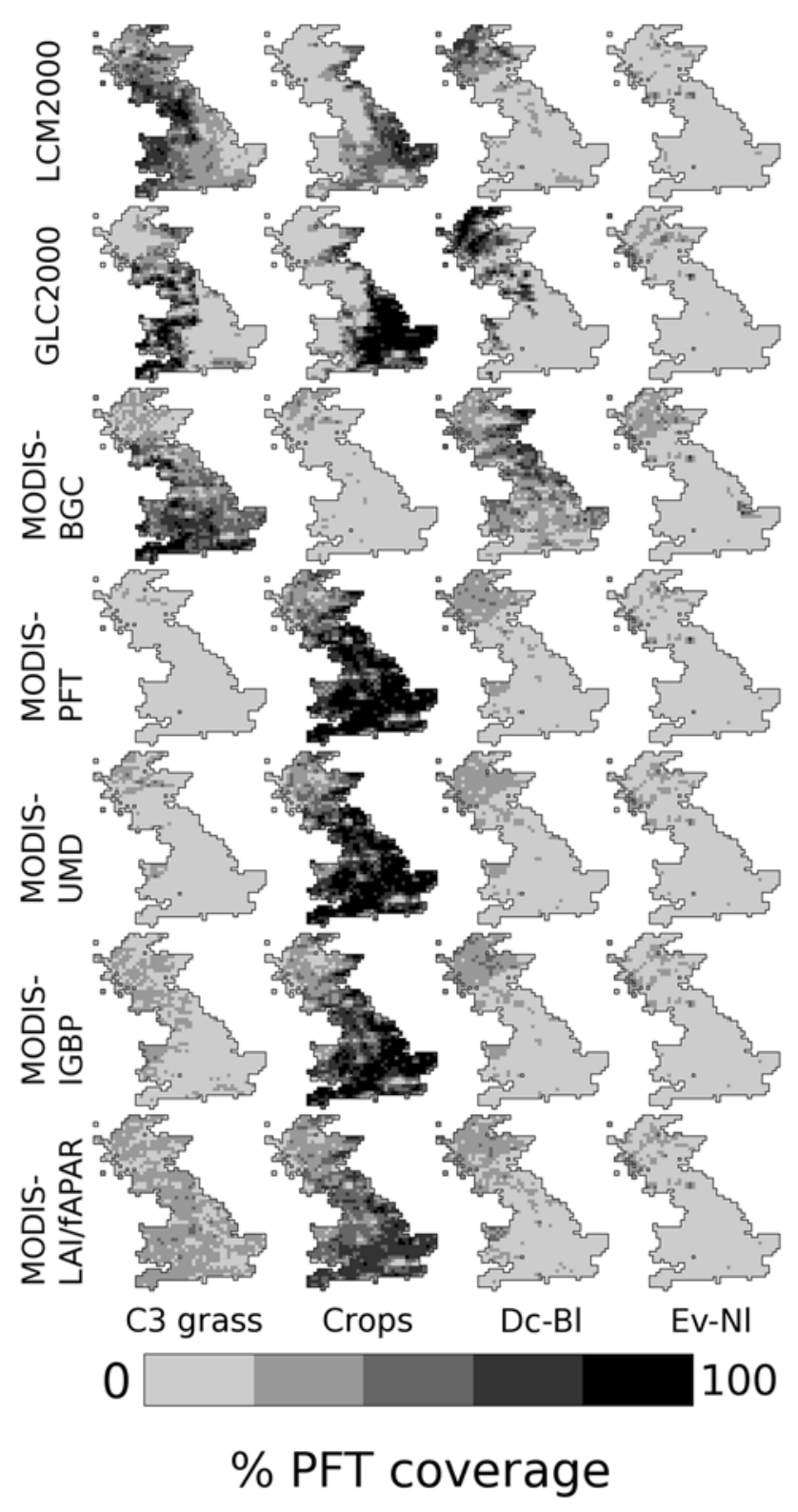

Figure 1. Proportions (from left to right) of the $\mathrm{C} 3$ grass, crop, deciduous broadleaf and evergreen needleleaf Plant Functional Types (PFTs) across Great Britain according to (a) LCM2000 (b) GLC2000 (c) MODIS-BGC (d) MODISPFT (e) MODIS-UMD (f) MODIS-IGBP (g) MODIS-LAI/ fAPAR. 
Table 2. Matrix Showing How 884 Regions Classified by Field Survey are Classified by LCM2000 at the PFT Level ${ }^{\mathrm{a}}$

\begin{tabular}{lllllll}
\hline & DcBl & EvNl & C3 & Crop & Urban & Total $(\%)$ \\
\hline DcB1 & 72 & 7 & 74 & 3 & 3 & 18.0 \\
EvNl & 11 & 50 & 6 & 0 & 0 & 7.6 \\
C3 & 38 & 2 & 254 & 17 & 10 & 36.3 \\
Crop & 5 & 1 & 33 & 212 & 7 & 29.2 \\
Urban & 1 & 0 & 3 & 6 & 69 & 8.9 \\
Total \% & 14.4 & 6.8 & 41.9 & 26.9 & 10.0 & 100 \\
\hline
\end{tabular}

${ }^{\mathrm{a}} \mathrm{DcBl}$ refers to deciduous broadleaf and EvNl to evergreen needleleaf. Units are numbers of regions assigned to each PFT. Totals are given as percentages. Columns refer to field survey data, and rows refer to LCM2000.

consequent fundamental limitation of land cover schemes based on such data. The urban/bare class is also underestimated by around $30 \%$ (relative) or more, largely due to confusion with crops and $\mathrm{C} 3$ grass. This arises because small rural areas are picked up by LCM2000 but not by the moderate resolution satellite products, and illustrates that loss of detail at coarser scales may bias land cover (and hence carbon flux) estimates.

[16] The spatial structures underlying the values given in Table 3 are shown in Figure 1 and reveal clear differences between the different products. GLC2000 produces similar spatial patterns of land cover to LCM2000, but with differences in proportions. Two notable features are (1) a sharper divide between $\mathrm{C} 3$ grasses in the west and crops in the east in GLC2000 and (2) a higher proportion of deciduous broadleaf in northwest Scotland, at the expense of C3 grass. Fritz et al. [2003] report an accuracy of $50.0 \%$ for the British portion of GLC2000 when compared with the CORINE (Coordination of Information on the Environment) database. This difference may partly be due to discrepancies in production techniques. A study by Mayaux et al. [2006] suggested a global accuracy of $68.6 \%$ in GLC2000, based on 1265 samples sites. For MODIS-BGC, the crop class is almost absent except in the far northwest, as a result of the assignment rules shown in Tables $1 \mathrm{a}-1 \mathrm{~g}$, while over much of the country the deciduous broadleaf class is enhanced. Most of the C3 grass PFT derives from the evergreen broadleaf class, as discussed in section 2.2. The other four MODIS products all have similar patterns, particularly the PFT and UMD products, but with a clear tendency to transform crops (which dominate the PFT and UMD products) into C3 grasses as we progress through the PFT, UMD, IGBP and LAI/fAPAR products. Globally, comparison of the MODIS
Table 4a. Matrices Showing the Majority PFT Assigned by LCM2000 and by the Other Land Cover Products for the 999 1/6th Degree Grid Cells Covering Great Britain: GLC2000

\begin{tabular}{llcllc}
\hline & DcBl & EvNl & C3 & Crop & Urban \\
\hline DcBl & 93 & 3 & 15 & 2 & 0 \\
EvN1 & 0 & 8 & 4 & 0 & 0 \\
C3 & 144 & 4 & 262 & 72 & 4 \\
Crop & 0 & 0 & 19 & 285 & 0 \\
Urban & 3 & 5 & 4 & 28 & 44 \\
\hline
\end{tabular}

${ }^{\mathrm{a}}$ Rows correspond to LCM2000 and columns to the other land cover products. DcBl refers to deciduous broadleaf and EvNl to evergreen needleleaf. The leading diagonal of the matrix contains the number of grid cells for which the LCM2000 agrees with the other land cover products in question. Off-diagonal elements show the number of grid cells that disagree and the nature of that disagreement - i.e. the number of grid cells of a given PFT in the land cover product (indicated by the column) that are classified as a different PFT in the LCM2000 (indicated by the row).

IGBP classification against the GLC2000 showed a perpixel agreement of less than $60 \%$ [Giri et al., 2005].

[17] Each grid cell may contain contributions from every PFT, so that simple measures cannot fully capture the differences between the moderate resolution land cover classifications. However, a coarse way of comparing them with LCM2000 is in terms of the majority PFT within a grid cell, as is done in Tables $4 \mathrm{a}-4 \mathrm{f}$.

[18] Tables $4 \mathrm{a}-4 \mathrm{f}$ indicate that all classifications, but particularly GLC2000 and MODIS-BGC, show relatively large amounts of deciduous broadleaf where LCM2000 shows $\mathrm{C} 3$ grasses. This is because the other products have a tendency to classify grass as shrubs, and the latter are assigned to the deciduous broadleaf PFT. Also clear is that almost all the $\mathrm{C} 3$ grass is assigned to crops in all the MODIS classifications except MODIS-BGC (which has no crop class).

[19] A useful measure of overall agreement between two classifications is given by the proportion of grid cells in which they agree on the dominant PFT. The agreement between LCM2000 and the other products can be easily calculated from Tables $4 \mathrm{a}-4 \mathrm{f}$. The percentage agreements are as follows: GLC 69.3\%; MODIS BGC 39.9\%; MODIS PFT 41.7\%; MODIS UMD 41.9\%; MODIS IGBP 46.4\%; MODIS LAI/fAPAR 44.5\%. The GLC2000 agrees best with LCM 2000 , at nearly $70 \%$ and none of the MODIS classifications exhibit agreement greater than $47 \%$. For some areas, however, GLC2000 consistently performs worse than the MODIS products (for example, in the proportion of deciduous broadleaf forest in northern Scotland). This may be due to there being fewer spectral wave bands on the

Table 3. Proportions of the Five PFTs for Great Britain Derived From the Various Land Cover Products, Given as Percentages

\begin{tabular}{lccccc}
\hline \multicolumn{1}{c}{ Land Cover } & Deciduous Broadleaf (\%) & Evergreen Needleleaf (\%) & C3 Grasses (\%) & Crops (\%) & Urban/Bare (\%) \\
\hline LCM2000 & 17.2 & 5.8 & 40.4 & 24.3 & 12.3 \\
GLC2000 & 20.5 & 5.2 & 28.6 & 38.6 & 7.0 \\
MODIS-BGC & 32.5 & 10.0 & 42.7 & 6.0 & 8.7 \\
MODIS-PFT & 11.4 & 5.8 & 8.3 & 65.7 & 8.7 \\
MODIS-UMD & 11.7 & 7.6 & 8.7 & 8.3 & 8.7 \\
MODIS-IGBP & 12.7 & 7.6 & 24.1 & 46.9 \\
MODIS-LAI/FAPAR & 14.2 & 6.2 & & & 8.7 \\
\hline
\end{tabular}


Table 4b. As in Table 4a, but for MODIS-BGC ${ }^{\text {a }}$

\begin{tabular}{llllll}
\hline & DcB1 & EvNl & C3 & Crop & Urban \\
\hline DcB1 & 51 & 37 & 10 & 14 & 1 \\
EvN1 & 4 & 7 & 1 & 0 & 0 \\
C3 & 171 & 14 & 282 & 13 & 6 \\
Crop & 94 & 7 & 190 & 0 & 13 \\
Urban & 6 & 3 & 16 & 0 & 59 \\
\hline
\end{tabular}

${ }^{\mathrm{a}}$ For explanation, see footnote to Table $4 \mathrm{a}$.

VEGETATION instrument (the principal data source for GLC2000) than on MODIS and hence an inherently weaker ability to discriminate between some classes.

\section{Carbon Flux Calculations}

[20] In this section, we examine the effects of using the different land cover products described in section 2 on carbon flux calculations by the Sheffield Dynamic Global Vegetation Model.

\subsection{Sheffield Dynamic Global Vegetation Model}

[21] In common with most DVMs, the Sheffield Dynamic Global Vegetation Model (SDGVM) calculates the stores and dynamics of carbon and water in the vegetation-soil system. It incorporates components that represent vegetation biophysics and dynamics (photosynthesis, phenology, evapotranspiration, nitrogen cycling, mortality, succession and disturbance), hydrology, and soil carbon respiration and storage [Woodward and Lomas, 2004]. Photosynthesis and stomatal conductance are modeled as functions of temperature and soil moisture. Soil dynamics are calculated using the CENTURY model [Parton et al., 1987]. Calculations are performed on $1 / 6^{\circ}$ grid cells, and there are no interactions between cells.

[22] PFTs are parameterized within the SDGVM by their phenological and physiological characteristics, such as leaf lifespan and photosynthetic efficiency. As noted in section 2 , only four of the SDGVM PFTs are relevant in Great Britain: deciduous broadleaf, which consists of trees and shrubs that lose their foliage annually; evergreen needleleaf, which consists predominantly of coniferous trees in Great Britain; and C3 grasses and crops, which differ in that crops are harvested at the end of the year, thus having an artificially shortened leaf lifespan, and the harvested biomass is removed from the system. There is also a noncontributing PFT, corresponding primarily to urban areas. For Great Britain, which is generally not water limited, phenological parameters such as those controlling budburst and senescence will have some of the largest impacts on the carbon budget. These are modeled as a function of the

Table 4c. As in Table 4a, but for MODIS-PFT ${ }^{\mathrm{a}}$

\begin{tabular}{llllll}
\hline & DcBl & EvN1 & C3 & Crop & Urban \\
\hline DcB1 & 47 & 5 & 4 & 56 & 1 \\
EvNl & 0 & 10 & 0 & 2 & 0 \\
C3 & 26 & 3 & 7 & 447 & 3 \\
Crop & 0 & 0 & 0 & 299 & 5 \\
Urban & 2 & 5 & 0 & 23 & 54 \\
\hline
\end{tabular}

${ }^{\mathrm{a}}$ For explanation, see footnote to Table $4 \mathrm{a}$.
Table 4d. As in Table 4a, but for MODIS-UMD ${ }^{\mathrm{a}}$

\begin{tabular}{llllll}
\hline & DcB1 & EvNl & C3 & Crop & Urban \\
\hline DcB1 & 41 & 2 & 12 & 57 & 1 \\
EvN1 & 1 & 9 & 0 & 2 & 0 \\
C3 & 20 & 3 & 16 & 443 & 4 \\
Crop & 0 & 0 & 0 & 299 & 5 \\
Urban & 5 & 3 & 0 & 22 & 54 \\
\hline
\end{tabular}

${ }^{\mathrm{a}}$ For explanation, see footnote to Table $4 \mathrm{a}$.

growing degree day and because they control the length of the growing season difference in these parameters between PFTs will result in differences in the uptake of carbon. The specific leaf area, which varies between PFT, governs the cost to the plant in carbon of maintaining leaves. Other parameters that contribute to differences in the carbon budget between the PFTs include the leaf nitrogen content, xylem conductivity, water potential and wood density.

[23] Inputs needed to run the SDGVM include soil data, taken here from the International Satellite Land Surface Climatology Project, http://www.gewex.org/islscp.html [Sellers et al., 1995; Meeson et al., 1995], and climate data for the period 1900-2000 from the University of East Anglia Climate Research Unit (CRU) [Mitchell et al., 2002; Mitchell and Jones, 2005]. The SDGVM was first run for 500 years with climate data for each year randomly selected from the first 20 years of the CRU data. This "spinup" stabilizes the carbon pools and provides the initial state for all the model runs reported in sections 3.2.1 and 3.2.2. This assumes a steady state at the beginning of the 20th century. The model runs themselves were carried out for the whole of the 20th century using the full CRU climate data set and including transient $\mathrm{CO}_{2}$ changes. This was performed for each of the land covers being analyzed.

\subsection{Impact of Land Cover on Carbon Fluxes}

[24] A first step in comparing carbon fluxes for different land covers was to calculate the GPP, NPP and NEP that would occur in the year 2000 if Great Britain was completely covered by each of the individual PFTs. Maps of the resulting fluxes are shown in Figure 2.

\subsubsection{Single-PFT Calculations}

[25] Before considering full land cover calculations, it is valuable to use the single-PFT calculations in Figure 2 to provide insight into how differences in land cover lead to differences in carbon fluxes and which types of misclassification have the biggest effect on flux estimates.

[26] Figure 2a shows increasing GPP in almost all grid cells as the cover type changes from crops to deciduous broadleaf to grassland to evergreen needleleaf. The crop and

Table 4e. As in Table 4a, but for MODIS-IGBP ${ }^{\mathrm{a}}$

\begin{tabular}{lccllc}
\hline & DcBl & EvNl & C3 & Crop & Urban \\
\hline DcB1 & 81 & 1 & 3 & 27 & 1 \\
EvNl & 1 & 10 & 0 & 1 & 0 \\
C3 & 49 & 6 & 19 & 404 & 8 \\
Crop & 1 & 0 & 0 & 296 & 7 \\
Urban & 5 & 3 & 0 & 18 & 58 \\
\hline
\end{tabular}

${ }^{\mathrm{a}}$ For explanation, see footnote to Table $4 \mathrm{a}$. 
Table 4f. As in Table 4a, but for MODIS-LAI/fAPAR ${ }^{\mathrm{a}}$

\begin{tabular}{lccccc}
\hline & DcB1 & EvN1 & C3 & Crop & Urban \\
\hline DcB1 & 59 & 10 & 9 & 34 & 1 \\
EvN1 & 2 & 9 & 0 & 1 & 0 \\
C3 & 59 & 5 & 24 & 391 & 7 \\
Crop & 1 & 0 & 0 & 292 & 11 \\
Urban & 4 & 6 & 0 & 13 & 61 \\
\hline
\end{tabular}

${ }^{\mathrm{a}}$ For explanation, see footnote to Table $4 \mathrm{a}$.

deciduous broadleaf PFTs have similar values of GPP, which are much larger than the GPPs of the $\mathrm{C} 3$ grass and evergreen needleleaf PFTs (which are also similar). Thus confusion between evergreen needleleaf and C3 grass, or deciduous broadleaf and crops, causes less difference in GPP than other misclassifications.

[27] The picture is more complex for NPP, since increased photosynthesis is associated with enhanced plant respiration. Figure $2 \mathrm{~b}$ shows a general increase in NPP as the land cover changes from deciduous broadleaf to evergreen needleleaf to grass to crops, with grass and needleleaf being of similar magnitude. Deciduous broadleaf is markedly less productive than the other PFTs over much of the country.

[28] Further complication arises when soil respiration is taken into account to estimate NEP (Figure 2c), with the spatial pattern being partly determined by soil type. The more "natural" cover types show similar patterns, with NEP increasing from grass to deciduous broadleaf to evergreen needleleaf, while crops do not exhibit as much spatial structure.

\subsubsection{Full Land Cover Calculations}

[29] Flux estimates were calculated for each land cover using the SDGVM, and Figures $3 a-3 c$ illustrates how these deviate from the LCM2000 estimates. The similar structures of the MODIS-PFT, -UMD, -IGBP and -LAI/fAPAR PFT maps (Figure 1) carry over to similarity in flux difference maps. Therefore, despite a slight tendency for flux differences to decrease in all fluxes as we move through this MODIS sequence, the four MODIS products are grouped together in the following discussion. In contrast, both
MODIS-BGC and GLC2000 show distinctly different patterns, reflecting the dissimilar structures of their PFT maps.

[30] For GPP (Figure 3a), it can be seen that for GLC2000, only a small number of grid cells have large deviations from LCM2000. There is a broadly even scatter of positive and negative differences, the latter arising largely from misclassifying grassland as either crops or deciduous broadleaf. MODIS-BGC exhibits much higher GPP than LCM2000 in the southeast, mainly because of assigning crops to grassland or deciduous broadleaf. The other MODIS products significantly underestimate GPP on the west side of Great Britain, because of misclassifying grassland and upland heath as crops.

[31] For NPP (Figure 3b), the most obvious feature of the GLC2000 plot is the overestimate of NPP in the southeast (other than London); this is associated with misclassifying $\mathrm{C} 3$ grasses and deciduous broadleaf as crops. The interpretation of MODIS-BGC is more complex. In the far northwest, crops are overestimated and deciduous broadleaf are underestimated, leading to an overall overestimate of NPP. Underestimation of the crop class down the east of the country causes underestimates in NPP. For the other MODIS products, the main cause of the observed overestimate of NPP in the west of the country is again misclassification of grassland and upland heath as crops.

[32] The NEP plots in Figure 3c have similar structure to the NPP plots. However, converting NPP to NEP involves subtracting the difference between the soil fluxes of the given land cover and LCM2000. The difference of the scales in Figures $3 b$ and $3 c$ indicates that this difference is significant.

[33] An additional effect in all the plots in Figures $3 a-3 c$ is that urban areas show a positive bias relative to LCM2000 in all the moderate resolution products. This is caused by systematic underestimation of noncontributing areas (see Table 3). (Note that the NEP bias can be negative if urban areas are misclassified as a PFT whose NEP is negative, but in practice the estimated NEPs are predominantly positive.) Since the LCM2000 itself slightly underestimates the proportion of the non-contributing PFT (see

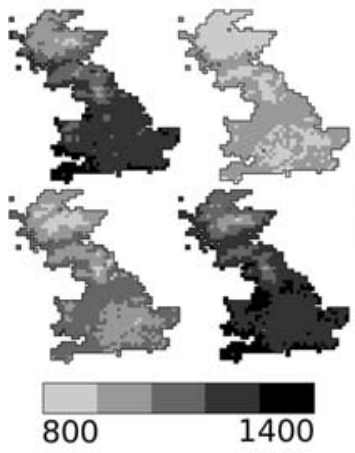

a) GPP

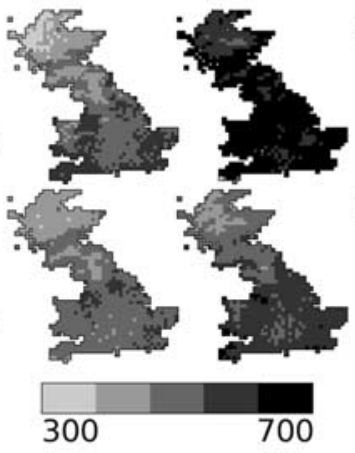

b) NPP

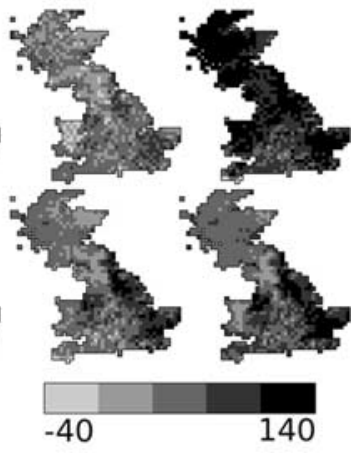

c) NEP

Figure 2. Estimated carbon fluxes for the year $2000\left(\mathrm{gCm}^{-2} \mathrm{a}^{-1}\right)$ assuming Great Britain is entirely covered by C3 grasses, crops, evergreen needleleaf and deciduous broadleaf; clockwise from top left in each case. 


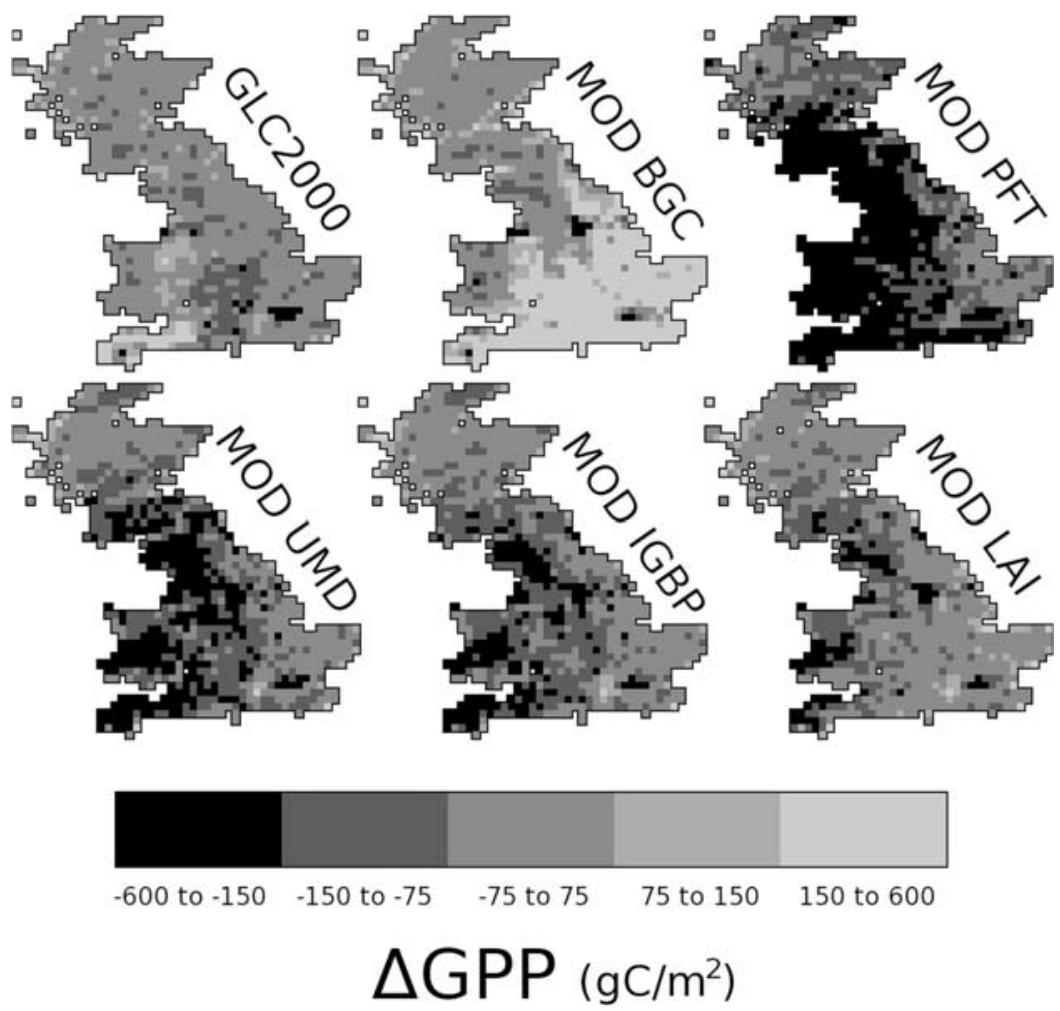

Figure 3a. Differences between Gross Primary Production (GPP) predicted using LCM2000 and the other land cover products. Dark (light) areas indicate under (over)-prediction with respect to LCM2000. From the top left, moving clockwise the land cover classification used is GLC2000, MODIS-BGC, MODIS-PFT, MODIS LAI/fAPAR, MODIS IGBP and MODIS UMD.

Table 2), the true biases in the other products will be even stronger.

[34] It can be seen from Table 5 that GLC2000 most consistently reproduces all the LCM2000 fluxes. The MODIS-BGC classification provides more accurate overall NPP and NEP estimates, but the analysis above indicates that this arises from fortuitous cancellation of differences in the flux contributions of the incorrectly assigned PFTs. For the other MODIS products, all the estimates improve moving through the PFT, UMD, IGBP and LAI/fAPAR products. In addition to the carbon fluxes, Table 5 shows the model predictions of total biomass (above and below ground) for the year 2000. This confirms the observation that the results of obtained using LCM2000 are most closely reproduced by those from GLC2000. The MODIS-BGC classification is markedly the most different from LCM2000 for biomass estimates.

[35] Table 5 also indicates the percentage differences relative to LCM2000. While these do not exceed $20 \%$ for GPP and NPP, they are much larger for NEP. This is partly because NEP is recovered by subtracting two large fluxes, the plant and soil respiration, from the GPP, so that absolute differences in the NEP become relatively more significant. Notably, the aggregate autotrophic respiration (GPP - NPP) varies very widely for different products, both in absolute terms (from 251 to $623 \mathrm{gC} \mathrm{m}^{-2} \mathrm{a}^{-1}$ ) and as a proportion of GPP (from $29 \%$ to $56 \%$ ), while the aggregate heterotrophic respiration (NPP - NEP) varies from only 447 to $537 \mathrm{gC} \mathrm{m}^{-2} \mathrm{a}^{-1}$ across all products. The ratio of soil respiration to NPP varies from $86 \%$ to $91 \%$, indicating that the system is accumulating carbon for the year 2000. The system is spun up to equilibrium at the start of the 20th century, but because of transient $\mathrm{CO}_{2}$ and climate during the run-proper the system moves out of equilibrium on an annual timescale.

[36] Included in Table 5, by way of comparison with the fluxes, are model estimates of total standing biomass derived by the SDGVM from each of the land covers. The magnitudes of the differences in biomass relative to the LCM2000 follow the same order as for GPP. The MODIS-BGC classification shows the greatest relative difference $(43 \%)$, strengthening the postulation that its good result for NPP and NEP is fortuitous. The explanation for this large overestimate in biomass is simply that the MODIS-BGC predicts a much large proportion of Great Britain to be covered by the woody PFTs (i.e., deciduous broadleaf and evergreen needleleaf) than the nonwoody PFTs.

\section{Discussion}

[37] A critical concern in model-based estimates of carbon flux is their reliability, in the presence of uncertainties in the input data and in their representation of biogeochem- 


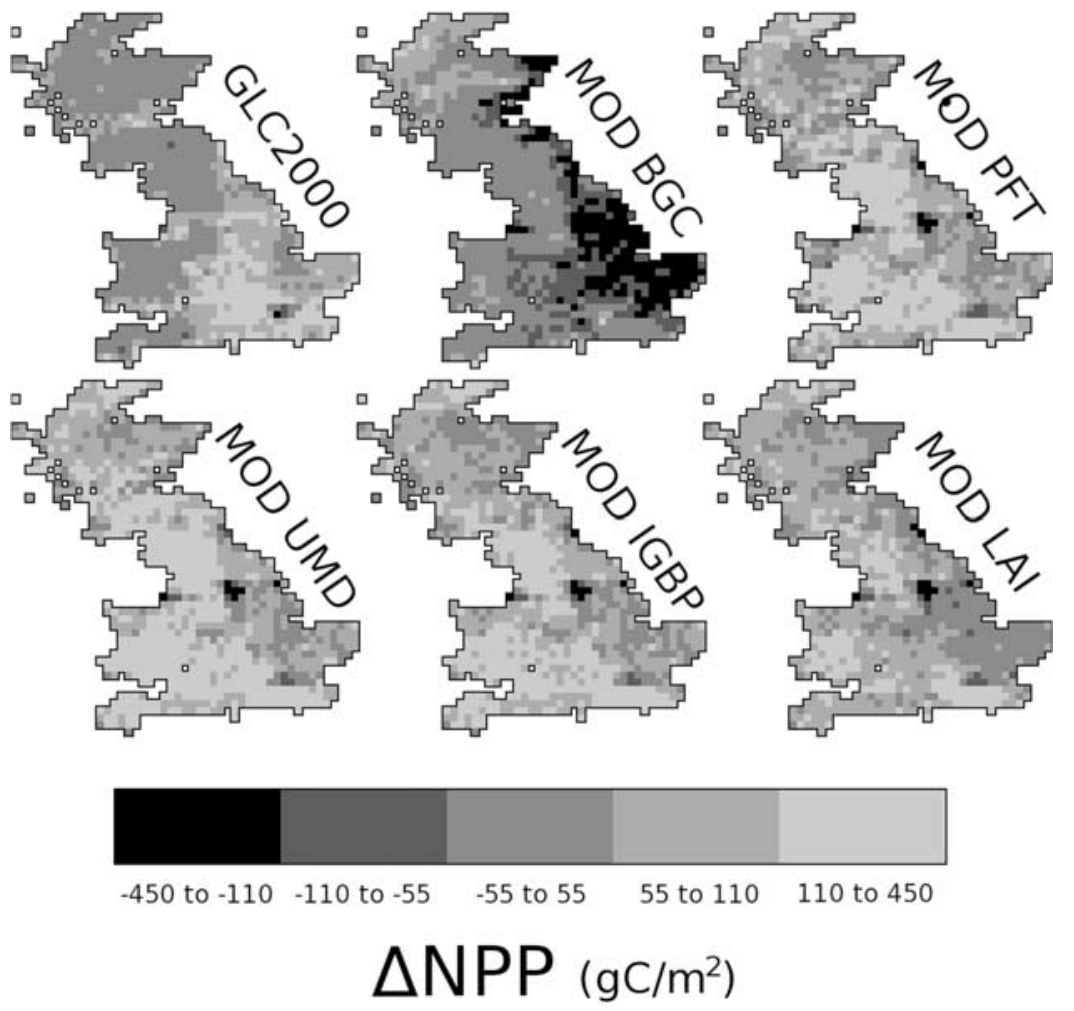

Figure 3b. Differences between Net Primary Production (NPP) predicted using LCM2000 and the other land cover products. Dark (light) areas indicate under (over)-prediction with respect to LCM2000. From the top left, moving clockwise the land cover classification used is GLC2000, MODIS-BGC, MODISPFT, MODIS LAI/fAPAR, MODIS IGBP and MODIS UMD.

ical processes. The results above make clear that inadequacy in land cover information is a major source of such uncertainty. It arises from three main factors: biases due to spatial scale, uncertainty due to the arbitrary rules for the assignment of land cover types to PFTs and uncertainty due to misclassification.

[38] Separating the effects that lead to uncertainties in carbon calculations is difficult and spatially dependent, and where there are complex mosaics of PFTs with very different flux behaviors, the effects of spatial resolution will be subtle. Spatial-scale matters since classification tends to select the majority class within a pixel (this is not always true: a small bright area surrounded by a larger dark region may dominate the signal from a pixel). Thus, as the spatial scale coarsens, larger areas of the land surface are represented by a single cover type. The implications for carbon flux calculations depend on the degree of subpixel heterogeneity and the amount by which the fluxes of the minority classes differ from those of the majority class. For Great Britain, one effect is an overall positive bias in the flux predictions for the $1 \mathrm{~km}$ classifications, because small areas contributing no biospheric flux, especially urban areas, are missed at the coarser resolution. This is particularly evident in the NPP and NEP calculations (Figures $3 b$ and $3 c$ ). For large urban areas the reverse effect is seen, resulting in a negative bias in flux predictions: small areas of vegetation (such as parks) are excluded by the coarse-scale land covers and consequently are not included in flux calculations.

[39] Problems of spatial scale also occur in discriminating between grasses and crops. In Great Britain, these PFTs dominate the landscape (the LCM2000 reports 40.4\% coverage by grass and $24.3 \%$ by crops). Confusion between crops and grasses is the main source of uncertainty in the MODIS classifications shown in Figure 1 and can produce large differences in all fluxes (see Figure 2). While grasses dominate in the west and crops in the east, they often coexist in highly heterogeneous mosaics, so that high spatial resolution is needed to separate them. However, high resolution alone is insufficient, since they can possess very similar spectral signatures, depending on their phenological stage.

[40] An attempt to correct moderate resolution land cover for subpixel structure is provided by the MODIS Vegetation Continuous Fields (VCF) product [DeFries et al., 1999, 2000; Hansen et al., 2002, 2003]. This consists of global estimates of percentage of forest cover at $500 \mathrm{~m}$ resolution and can be updated every 3-6 months. Unfortunately, estimates of percentage cover for nonforest PFTs are currently not provided, so it is unclear how to assign the remaining percentage when forest cover is significantly less than $100 \%$. Plans exist, however, to extend the VCF scheme to nonforest land cover, when it will be well-matched to the needs of DVMs. Disney and Lafont [2004] assessed the 


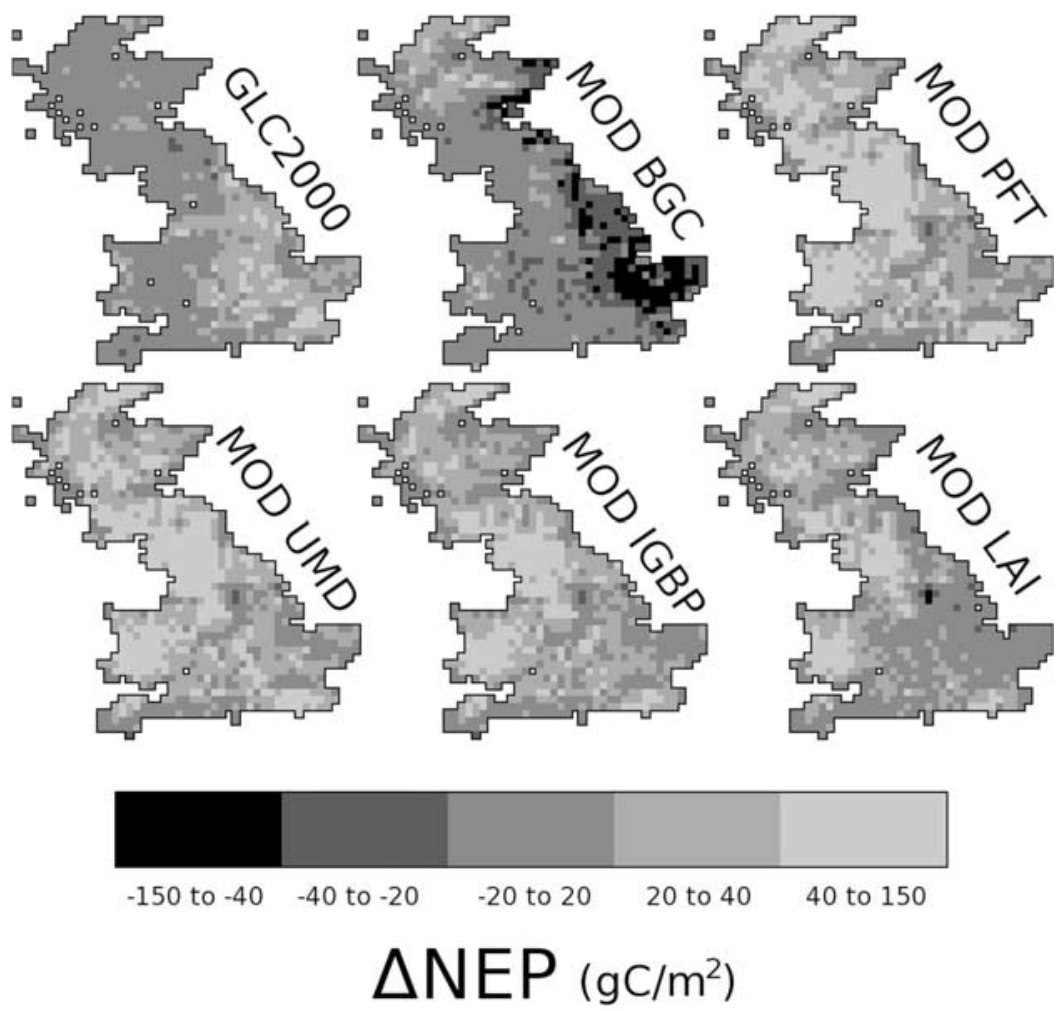

Figure 3c. Differences between Net Ecosystem Production (NEP) predicted using LCM2000 and the other land cover products. Dark (light) areas indicate under (over)-prediction with respect to LCM2000. From the top left, moving clockwise the land cover classification used is GLC2000, MODIS-BGC, MODIS-PFT, MODIS LAI/fAPAR, MODIS IGBP and MODIS UMD.

accuracy of the VCF product by comparing it with a high spatial resolution database based on detailed ground survey by the UK Forestry Commission. The overall finding of this study was that the VCF tended to overestimate the proportion of forest cover.

[41] The ability to distinguish between different PFTs is limited by our ability to distinguish land cover types using samples of the reflected solar spectrum gathered by satellites. The impact of such fundamental limitations depends on the dissimilarity in the fluxes from the misclassified PFTs, but some types of misclassification are particularly important. For example, separating crops and grasses is problematic in several of the schemes assessed. This will significantly affect carbon budget calculations at regional to global scales because large parts of the globe are given over to cropping and grasslands, often in proximity, and the carbon fluxes from these two cover types are quite different. Errors in distinguishing moorland/upland heath from forest are also likely to have significant impacts at higher latitudes.

[42] When products are created from data covering different time periods, as is the case here (see section 2.1), land cover change can introduce further uncertainty. For Great Britain, this is not a major source of error [Haines-Young et $a l ., 2000]$ but it can be important in areas of rapid change, such as tropical forest [Ramankutty et al., 2007] where land cover change is thought to be a large factor in NEP. This is especially the case where natural ecosystems are being replaced by cropland and soil carbon is rapidly lost. The fact that many of the global satellite-derived products can be (and are) updated on an annual or subannual basis gives them a major advantage over other methods for monitoring this. Nonetheless, there is still considerable debate about whether these products have sufficient accuracy for this potential to be fully exploited [Houghton, 2003; Achard et al., 2004]. The types of uncertainty discussed in this study will impose a practical limit to the level of land cover change that can be detected. Taking as example the GLC2000 there is a significant overestimation of deciduous broadleaf trees where the LCM2000 shows grassland.

Table 5. Mean Fluxes and Biomass for Great Britain for the Year 2000 Predicted by the SDGVM Using the Different Land Cover Classifications $^{\mathrm{a}}$

\begin{tabular}{lcccc}
\hline Land Cover Product & GPP & NPP & NEP & Biomass \\
\hline LCM2000 & 1025 & 521 & 53 & 1712 \\
GLC2000 & $1019(-0.5)$ & $576(10.6)$ & $66(25.4)$ & $1741(1.7)$ \\
MODIS-BGC & $1115(8.8)$ & $492(-5.6)$ & $45(-14.8)$ & $2454(43.3)$ \\
MODIS-PFT & $862(-15.8)$ & $611(17.2)$ & $88(67.0)$ & $1345(-21.4)$ \\
MODIS-UMD & $925(-9.6)$ & $625(20.0)$ & $88(66.1)$ & $1483(-13.3)$ \\
MODIS-IGBP & $947(-7.5)$ & $608(16.9)$ & $81(54.1)$ & $1538(-10.1)$ \\
MODIS-LAI/fAPAR & $983(-3.9)$ & $587(12.8)$ & $73(39.1)$ & $1572(-8.1)$ \\
\hline
\end{tabular}

${ }^{a}$ The percentage differences relative to LCM2000 are indicated in parentheses. Units for fluxes are $\mathrm{gC} \mathrm{m}^{-2} \mathrm{a}^{-1}$ and units for biomass are $\mathrm{gC} \mathrm{m}^{-2}$. GPP is Gross Primary Production; NPP is Net Primary Production; NEP is Net Ecosystem Production. 
Clearly changes in land cover from deciduous trees to grassland may be obscured by this type of confusion. Similar examples exist for all of the coarse-scale land covers considered here, most notably between grasses and crops.

[43] The simple rules we have used to assign land cover classes to PFTs could introduce or compound uncertainties, particularly when classes contain more than one PFT (e.g., mixed forest). It should be noted, however, that the transformation rules are relatively self evident for the most part with the exception of some of the MODIS classes. In this study the issue of mixed class transformations has little effect for GLC2000 in which such classes (see Tables 1a$1 \mathrm{~g}$ ) cover less than $0.5 \%$ of Great Britain. Any such bias would be expected to progressively increase for the MODIS PFT, UMD, IGBP and LAI/fAPAR products, in which mixed classes occupy $5.0 \%, 17.7 \%, 29.3 \%$ and $37.5 \%$ of Great Britain, respectively. In fact, Figures $3 a-3 c$ shows that the carbon flux estimates improve in this sequence, as the uncertainties are dominated by other forms of misclassification. MODIS-BGC has no classes involving more than one PFT, but presents special problems because of its lack of a crop class and its gross over-representation of the evergreen broadleaf class in Great Britain, as noted in section 2.2 .

[44] Although biases due to mixed classes are not a major source of uncertainty, gross misassignments of classes to PFTs could be. To prevent this, we have used local knowledge, such as placing the MODIS-LAI/fAPAR broadleaf forest class into the broadleaf deciduous leaf PFT. In other parts of the world, it would more correctly be assigned to evergreen broadleaf. This indicates the need to take regional conditions into account when assigning classes to PFTs.

[45] We have not discussed inadequacies in the classification algorithms themselves. However, algorithm performance is normally assessed on the basis of tests like those performed here, and our results provide clear indications of relative performance, albeit for a particular region.

\section{Conclusions}

[46] By taking advantage of a high-resolution land cover map that represents the best current understanding of land cover in Great Britain, it has been demonstrated that uncertainty in satellite-derived land cover introduces considerable uncertainty into model-based carbon flux estimates, for the following reasons: biases arising from inability to resolve heterogeneity in the landscape with moderate spatial resolution data; incorrect/uncertain transformation of land cover to PFTs; fundamental difficulties in discriminating some land cover types with a given data set and classification scheme.

[47] The different satellite-derived land cover products introduce uncertainties into the aggregated carbon flux and stock estimates with ranges of $254 \mathrm{gC} \mathrm{m}^{-2} \mathrm{a}^{-1}$ in GPP; $133 \mathrm{gC} \mathrm{m}^{-2} \mathrm{a}^{-1}$ in NPP; $43 \mathrm{gC} \mathrm{m}^{-2} \mathrm{a}^{-1}$ in NEP; and $1109 \mathrm{gCm}^{-2}$ in biomass relative to the LCM2000 highresolution land cover map of Great Britain. In percentage terms GPP exhibits differences from $-15.8 \%$ to $8.8 \%$, whereas for NEP the range is much larger, from $-14.8 \%$ to $67.0 \%$. Kennedy et al. [2008] have shown that uncertainty in PFT and soil parameters for England and Wales translates into an aggregated NEP standard deviation of $\sim 4.0 \mathrm{gC} \mathrm{m}^{-2}$ for the year 2000. This is much smaller the uncertainty arising from land cover, emphasizing the need to consider land cover as a crucial element in any uncertainty analysis of model-based carbon flux.

[48] Great Britain is particularly heterogeneous and consequently biases induced by inadequate spatial scale of the underlying land cover are fairly strong. Similar tendencies are likely, for example, in Northern Europe and South-East Asia, which contain a large proportion of heterogeneous managed agricultural regions. For more homogeneous regions, such as the Siberian boreal forests, such biases will tend to be smaller.

[49] Acknowledgments. This work was funded by the UK Natural Environment Research Council through the Centre for Terrestrial Carbon Dynamics. We are grateful to $\mathrm{CEH}$ and the Forestry Commission for provision of and help with data sets. We also extend our thanks to the two anonymous reviewers who helped to significantly improve the quality of this manuscript.

\section{References}

Achard, F., H. D. Eva, P. Mayaux, H.-J. Stibig, and A. Belward (2004), Improved estimates of net carbon emissions from land cover change in the tropics for the 1990s, Global Biogeochem. Cycles, 18, GB2008, doi:10.1029/2003GB002142.

Bartholomé, E., and A. Belward (2005), GLC2000: A new approach to global land cover mapping from Earth observation data, Int. J. Remote Sens., 26, 1959-1977, doi:10.1080/01431160412331291297.

Bonan, G. B., S. Levis, L. Kergoat, and K. W. Oleson (2002), Landscapes as patches of plant functional types: An integrated concept for climate and ecosystem models, Global Biogeochem. Cycles, 16(2), 1021, doi:10.1029/2000GB001360.

Cramer, W., et al. (2001), Global response of terrestrial ecosystem structure and function to and climate change: Results from six dynamic global vegetation models, Global Change Biol., 7, 357-373, doi:10.1046/ j.1365-2486.2001.00383.x.

DeFries, R. S., J. R. G. Townshend, and M. C. Hansen (1999), Continuous fields of vegetation characteristics at the global scale at $1 \mathrm{~km}$ resolution, J. Geophys. Res., 104, 16,911-16,925, doi:10.1029/1999JD900057.

DeFries, R. S., M. C. Hansen, J. R. G. Townshend, A. C. Janetos, and R. Loveland (2000), A new global 1-km dataset of percentage tree cover derived from remote sensing, Global Change Biol., 6, 247-254, doi:10.1046/j.1365-2486.2000.00296.x.

Disney, M. I., and S. Lafont (2004), Evaluation of the MODIS continuous tree cover map over the UK, paper presented at MODIS Vegetation Workshop, NASA, Univ. of Montana, Missoula, 17-19 August.

Foley, S., et al. (2005), Global consequences of land use, Science, 309, 570-574, doi:10.1126/science. 1111772 .

Fritz, S., et al. (2003), Harmonisation, mosaicing and production of the Global Land Cover 2000 database, Beta Version, EUR 20849, scientific report, 41 pp., Eur. Commiss., Luxembourg.

Fuller, R. M., G. M. Smith, J. M. Sanderson, R. A. Hill, A. G. Thomson, R. Cox, N. J. Brown, T. Clarke, P. Rothery, and F. F. Gerard (2002), Countryside Survey 2000 Module 7 land cover map 2000, final report, 102 pp., Cent. for Ecol. and Hydrol., Monks Wood, UK.

Giri, C., Z. Zhu, and B. Reed (2005), A comparative analysis of the Global Land Cover 2000 and MODIS land cover data sets, Remote Sens. Environ., 94, 123 -132, doi:10.1016/j.rse.2004.09.005.

Haines-Young, R., et al. (2000), Accounting for nature: Assessing habitats in the UK countryside, Tech. Rep. ISBN 185112460 8, 134 pp., Dept. of Transport Environ. Regions, London.

Hansen, M., and B. Reed (2000), A comparison of the IGBP DISCover and University of Maryland $1 \mathrm{~km}$ global land cover products, Int. J. Remote Sens., 21, 1365-1373, doi:10.1080/014311600210218.

Hansen, M. C., R. S. DeFries, J. R. G. Townshend, and R. Sohlberg (2000), Global land cover classification at $1 \mathrm{~km}$ spatial resolution using a classification tree approach, Int. J. Remote Sens., 21, 1331-1364, doi:10.1080/ 014311600210209

Hansen, M. C., R. S. DeFries, J. R. G. Townshend, R. Sohlberg, C. Dimiceli, and M. Carroll (2002), Towards an operational MODIS continuous field 
of percent tree cover algorithm: Examples using AVHRR and MODIS data, Remote Sens. Environ., 83, 303-319, doi:10.1016/S00344257(02)00079-2.

Hansen, M. C., R. S. DeFries, J. R. G. Townshend, M. Carroll, C. Dimiceli, and R. Sohlberg (2003), Global percent tree cover at a resolution of 500 meters: First results from the MODIS Vegetation Continuous Fields algorithm, Earth Interact., 7, 1-15, doi:10.1175/1087-3562(2003)007< 0001:GPTCAA $>2.0$.CO;2.

Houghton, R. A. (2003), Why are estimates of the terrestrial carbon balance so different?, Global Change Biol., 9, 500-509, doi:10.1046/j.13652486.2003.00620.x.

IPCC (2001), Climate Change 2001: The Scientific Basis. Contribution of Working Group 1 to the Third Assessment Report of the Intergovernmental Panel on Climate Change, edited by J. T. Houghton et al., 882 pp., Cambridge Univ. Press, Cambridge, UK.

Janssens, I. A., et al. (2003), Europe's terrestrial biosphere absorbs 7 to $12 \%$ of European anthropogenic $\mathrm{CO}_{2}$ emissions, Science, 300, 1538-1542, doi:10.1126/science.1083592.

Kennedy, M., C. Anderson, A. O'Hagan, M. Lomas, F. I. Woodward, J. P. Gosling, and A. Heinemeyer (2008), Quantifying uncertainty in the biospheric carbon flux for England and Wales, J. R. Stat. Soc. Ser. A, 171(1), $109-135$.

Lotsch, A., Y. Tian, M. A. Friedl, and R. B. Myneni (2003), Land cover mapping in support of LAI and FPAR retrievals from EOS-MODIS and MISR: Classification methods and sensitivities to errors, Int. J. Remote Sens., 24(10), 1997-2016, doi:10.1080/01431160210154858.

Loveland, T. R., and A. S. Belward (1997), The IGBP-DIS global $1 \mathrm{~km}$ land cover data set, DIScover: First results, Int. J. Remote Sens., 65(9), $1021-1031$.

Mayaux, P., et al. (2006), Validation of the Global Land Cover 2000 Map, IEEE Trans. Geosci. Remote Sens., 44(7), 1728-1739, doi:10.1109/ TGRS.2006.864370.

McCallum, I., M. Obersteiner, S. Nilsson, and A. Shivdenko (2006), A spatial comparison of four satellite derived $1 \mathrm{~km}$ global land cover datasets, Int. J. Appl. Earth Obs. Geoinformation, 8, 246-255, doi:10.1016/ j.jag.2005.12.002.

Meeson, B., F. Corprew, J. McManus, D. Myers, J. Closs, K.-J. Sun, D. Sunday, and P. Sellers (1995), ISLSCP Initiative I: Global Data Sets for Land-Atmosphere Models, 1987-1988 [CD-ROM], 1-5, NASA, Washington, D. C.

Meir, P., P. Cox, and J. Grace (2006), The influence of terrestrial ecosystems on climate, Trends Ecol. Evol., 21(5), 254-260, doi:10.1016/ j.tree.2006.03.005.

Mitchell, T., and P. D. Jones (2005), An improved method of constructing a database of monthly climate observations and associated high-resolution grids, Int. J. Clim. Change, 25, 693-712.

Mitchell, T., M. Hulme, and M. New (2002), Climate data for political areas, Area, 34, 109-112, doi:10.1111/1475-4762.00062.

Parton, W., D. Schimel, C. Cole, and D. Ojima (1987), Analysis of factors controlling soil organic matter levels in Great Plains grasslands, Soil Sci. Soc. Am. J., 51, 1173-1179.
Ramankutty, N., H. K. Gibbs, F. Achard, R. DeFries, J. A. Foley, and R. A Houghton (2007), Challenges to estimating carbon emissions from tropical deforestation, Global Change Biol., 13, 51-66, doi:10.1111/j.13652486.2006.01272.x.

Reich, P., D. Turner, and P. Bolstad (1999), An approach to spatially distributed modeling of net primary production (NPP) at the landscape scale and its application in validation of EOS NPP products, Remote Sens. Environ., 70, 69-81, doi:10.1016/S0034-4257(99)00058-9.

Running, S., R. Nemani, J. M. Glassy, and P. Thornton (1999), MODIS Daily Photosynthesis (PSN) and Annual Net Primary Production (NPP) Product (MOD17), algorithm theoretical basis document, version 3.0, 59 pp., NASA Goddard Space Flight Cent., Greenbelt, Md. (Available at http://modis.gsfc.nasa.gov/data/atbd/land_atbd.php, accessed 29 April)

Schimel, D. S. (1995), Terrestrial ecosystems and the carbon cycle, Global Change Biol., 1, 77-91, doi:10.1111/j.1365-2486.1995.tb00008.x.

See, L. M., and S. Fritz (2006), A method to compare and improve land cover datasets: Application to the GLC-2000 and MODIS land cover products, IEEE Trans. Geosci. Remote Sens., 44(7), 1740-1746, doi:10.1109/TGRS.2006.874750.

Sellers, P., et al. (1995), An overview of the ISLSCP Initiative I: Global data sets, in ISLSCP Initiative I Global Data Sets for Land-Atmosphere Models, 1987-1988 [CDROM], 1, NASA, Washington, D. C.

Sitch, S., V. Brovkin, W. von Bloh, D. van Vuuren, B. Eickhout, an A. Ganapolski (2005), Impacts of future land cover changes on atmospheric $\mathrm{CO}_{2}$ and climate, Global Biogeochem. Cycles, 19, GB2013, doi:10.1029/2004GB002311.

Strahler, A., D. Muchoney, J. Borak, M. Friedl, S. Gopal, E. Lambin, and A. Moody (1999), MODIS Land Cover and Land Cover Change, algorithm theoretical basis document, Tech. Rep. Version 5.0, 66 pp., EOSMODIS, NASA Goddard Space Flight Cent., Greenbelt, Md.

Townshend, J. (1994), Global data sets for land applications from the Advanced Very High-Resolution Radiometer: An introduction, Int. J. Remote Sens., 15, 3319-3332, doi:10.1080/01431169408954333.

Turner, D. P., W. B. Cohen, and R. E. Kennedy (2000), Alternative spatial resolutions and estimation of carbon flux over a managed forest landscape in western Oregon, Landscape Ecol., 15, 441-452, doi:10.1023/ A:1008116300063.

Woodward, F. I., and M. R. Lomas (2004), Vegetation dynamics: Simulating responses to climatic change, Biol. Rev. Camb. Philos. Soc., 79(3), 643-670, doi:10.1017/S1464793103006419.

M. Disney, P. Lewis, and T. Quaife, Department of Geography, University College London, Pearson Building, Gower Street, London WC1E 6BT, UK. (tquaife@geog.ucl.ac.uk)

M. Lomas and F. I. Woodward, Department of Animal and Plant Sciences, University of Sheffield, Alfred Denny Building, Western Bank, Sheffield S10 2TN, UK.

S. Quegan, Department of Applied Mathematics, University of Sheffield, Hicks Building, Hounsfield Road, Sheffield S3 7RH, UK. 